\title{
Performance Analysis of AODV, DSR and DYMO Protocols using Random Waypoint Mobility Model in MANET
}

\author{
Shobha Arya \\ Dept. of Computer Science \\ Gurukul Kangri University, \\ Haridwar
}

\author{
Nipur, PhD. \\ Dept. of Computer Science \\ Gurukul Kangri University, \\ Haridwar
}

\author{
Chandrakala Arya \\ Dept. of Computer Science \\ Pal College of Technology \& \\ Management, Haldwani
}

\begin{abstract}
The Mobile Ad Hoc Network is an infrastructure less, multihop ad hoc network because the intermediate nodes are used to transmit data from source to destination. This paper represents the simulation based study of network protocols for varying network load and mobility. In this paper three protocols AODV, DSR and DYMO are compared by using random waypoint mobility in few nodes with varying packet sizes in CBR traffic. Different parameters or metrics are used to evaluate the performance of protocols, which are data throughput, end-to-end delay and packet loss with varying data traffic CBR(Constant Bit Ratio) load over UDP using QualNet 5.0.2 simulator.
\end{abstract}

\section{Keywords}

MANET, AODV, DSR, DYMO, CBR and Random waypoint mobility model etc.

\section{INTRODUCTION}

The Mobile Ad Hoc Network (MANET) has no access point or central administration, so the nodes are free to move randomly. They have capability to change links from one node to other node. The Mobile Ad Hoc Network can be reconfigured so it can handle network topology changes and malfunctions in nodes. When the nodes are not in the communication range then the nodes can transfer data from one node to other node with the help of intermediate nodes. This Mobile Ad Hoc Network is used in rescue areas, medical and military applications etc.

The mobility is the big issue to determine routes. In mobile multi hop ad hoc network, it is difficult to determine route. A lot of researches have been done to decide the best routing algorithm. In this research paper, we have made a comparison and performance analysis of AODV, DSR and DYMO routing protocols when some nodes consist random way point mobility and traffic load is also varying. Different parameters or metrics are used for performance analysis packet loss, throughput, end-to-end delay, and aggregate good put and average jitter.

\section{DESCRIPTION OF THE PROTOCOLS}

The AODV, DSR and DYMO are On-demand routing (reactive) protocols. The AODV, DSR and DYMO protocols that are being studied in this paper are briefly explain below:

\subsection{Ad-Hoc On-Demand Distance Vector (AODV)}

Ad-Hoc On-Demand Distance Vector routing protocol is an improved form of Destination Sequenced Distance Vector
(DSDV) protocol. When a mobile node sends message to other node using AODV protocol, it first check its routing table to find the route (path). If it finds the route then it starts communication immediately, Otherwise the source node broadcast the route discovery packet called Route Request (RREQ). The neighbors broadcast the packet to their neighbors until it reaches its destination. The destination node replies to the route-request (RREQ) of source node with a route-reply (RREP) packet. For the valid path when a node forwards a route request (RREQ) packet to its neighbors, it stores the information in its table of the node from which the first copy of the route request came. This information is used to create the reverse path of route reply (RREP) packet. The intermediate nodes which reply to route requests, reply with latest information only. The route request packet ensures that the route is loop free by using sequence numbers.

Route Request (RREQ), Route Reply (RREP), Route Error (RERR) and HELLO messages are four types of packets or messages used by nodes for communication by AODV. For route discovery, Route Request (RREQ) and Route Reply (RREP) packets are used and for route maintenance, Route Error (RERR) and HELLO packets are used.

\subsection{Dynamic Source Routing (DSR)}

The dynamic source routing protocol (DSR) is a reactive or source routed on-demand routing protocol, allows any node to dynamically determine the route from source to the destination. Two main phases of this protocol are Route Discovery and Route Maintenance. It supports asymmetric routes and unidirectional links. When a source node wants to communicate with destination node, it first checks its routing table to find the route (path). If source node searches the route in its cache then it starts communication immediately, otherwise it broadcasts the Route Request (RREQ) packet. Each intermediate node forward this RREQ packet to its neighbors until it reaches to its destination. When the first Route Request (RREQ) packet arrives, the destination node sends a reply packet (RREP) to the source node from the same route in reverse direction of RREQ packet. The source node caches the route information of RREP packet for future use. The main difference that DSR is different from other protocol is it doesn't contain Hello messages. So it does not need exchange of periodic Hello messages or packets. That's why it is beacon-less.

If there is an error on link (hop), it generates route error (RERR) packet. The route error (RERR) packet informs the source node about the error then the source node eliminates the route from its cache which is used by that link. And if this route is still required then the source node starts a new route discovery process. 


\subsection{Dynamic MANET On-Demand (DYMO)}

Dynamic MANET On-Demand (DYMO) protocol consists multi hoping and unicast routing. When a node wants to communicate with another node, it searches the route in its cache. Otherwise it broadcasts a route request (RREQ) packet in the network for determining the route of destination node. The route request (RREQ) packet is forwarded by the intermediate nodes to their neighbors till it reaches to its destination. The destination node replies back a packet called route reply (RREP) to the source node. Each node has route information or routing table in its cache.

When a node gets a packet which doesn't contain a valid route or the route is broken for a destination, it generates Route Error (RERR) packet. This node updates its routing table by the list consisting the address and sequence number of the unreachable node, when RERR packet is generated. Its purpose is to inform additional routes that the additional routes are no longer available. The RERR packet informs other nodes about the link failure. The route discovery is processed by the source node if route is still required. The nodes use Hello packets or message to maintain paths to its neighbor node.

\section{LITERATURE REVIEW}

A lot of research work has been done for mobility of different protocols in Mobile Ad-Hoc Network like Performance Analysis of Ad Hoc Routing Protocols Using Random Waypoint Mobility Model in Wireless Sensor Networks [1], DYMO routing protocol Research and Simulation based on NS2 [2], Ad hoc Mobile Wireless Networks: Protocols and Systems [3], Comparative Study of Reactive and Proactive Routing Protocols Performance in Mobile Ad Hoc Networks [4], Performance Comparison of Multi-Path AODV and DSR protocols in Hybrid Mesh Networks [5], A Survey of Mobility Models in Wireless Ad hoc Networks [6], Performance Comparison and Analysis of Table- Driven and On-Demand Routing Protocols for Mobile Ad-hoc Networks [7], Performance Comparison of Trust-Based Reactive Routing Protocols [8], Routing approaches in mobile ad hoc networks [9], The broadcast storm problem in a mobile ad hoc network [10], Dynamic probabilistic broadcasting in MANETs [11], Comparison of broadcasting techniques for mobile ad hoc networks [12], Highly Dynamic Destination-Sequenced Distance-Vector Routing (DSDV)Routing [13], Highly Dynamic Destination-Sequenced Distance-Vector Routing (DSDV) Routing [14], The dynamic source routing protocol for mobile ad hoc networks for IPv4 [15], Dynamic source routing in ad hoc wireless networks [16], Dynamic MANET on demand (DYMO) routing protocol [17], TemporallyOrdered Routing Algorithm (TORA) Version 1 Functional Specification [18] and The Zone Routing Protocol (ZRP) for Ad Hoc Networks [19] etc. These research works describe the performance of various protocols using mobility models in mobile ad hoc networks. The mobility affects the performance of protocols.

\section{PROPOSED APPROACH}

The mobility model shows the mobility of mobile users, so the routes can change because of mobility of nodes in Mobile Ad-Hoc Network. It represents the mobility characteristics such as location, velocity and acceleration change over time of mobile users. Mobility is responsible for a faithful communication between nodes.

The Random Waypoint mobility is used in this model. In Random Waypoint Mobility, the nodes are free to move randomly without restriction. The destination, speed directions are all taken independently and randomly of other nodes during the simulation time. When a node moves independently and starts at a random location, it waits for a specified period known as pause time. Once this time expires, the mobile node choses a random location and speed. In this simulation, it is between 0 and max. speed of $10 \mathrm{~m} / \mathrm{s}$. Upon arrival, the mobile node again remains stationary for the pause time and chooses a new random location with a new randomly chosen speed. It is repeated throughout the simulation.

In this simulation, Random Waypoint mobility is applied on few selected nodes in MANET. With this mobility a lot of changes appear during transfer of packets in different protocols. In this approach, in a scenario of 100 nodes, when two nodes transfer packets with Constant Bit Rate (CBR) with varying packet sizes and some of nodes have random waypoint mobility then performance of different protocols is analyzed at different parameters.

In this research, a comparison and performance analysis of AODV, DSR and DYMO routing protocols is performed when some nodes consists random way point mobility. It is based on IEEE 802.11. Different parameters i.e. packet loss, data throughput, end-to-end delay, aggregate good put and average jitter with varying data traffic CBR (Constant Bit Ratio) load over UDP using QualNet 5.0.2 simulator shows the performance of protocols. It helps to generate good movement model to evaluate AODV, DSR and DYMO routing protocols.

\section{SIMULATION SETUP AND EXPERIMENTAL ANALYSIS}

The proposed analysis is performed by the QualNet 5.0.2 network simulator. There are 100 nodes placed uniformly over the region of $1500 \mathrm{~m} \times 1500 \mathrm{~m} \&$ data is transferred from source node 51 to destination node 14 with a Constant Bit Rate. To analyze the mobility model in different routing protocols (AODV, DSR and DYMO) the random waypoint mobility is applied on 1,7,24,26,31,36 nodes out of 100 nodes. MAC protocol defined by IEEE $802.11 \mathrm{a} / \mathrm{g}$ is used for wireless LANs with a channel data frequency of $2.4 \mathrm{GHz}$.

Traffic sources of Constant Bit Rate (CBR) based on User datagram Protocol (UDP) have been used. The End Time is $20 \mathrm{sec}$, Start Time is $0 \mathrm{sec}$ and total number of items to send from node 51 to node 14 is 20 . The packet size is varied as 512bytes, 712 bytes and 1024 bytes to analyze the performance of AODV, DSR and DYMO. Different simulation parameters list is given below are used for analysis:

Table 1: Simulation Parameters

\begin{tabular}{|l|l|}
\hline \multicolumn{1}{|c|}{ Parameter } & \multicolumn{1}{c|}{ Value } \\
\hline Terrain Dimension & $1500 \mathrm{mX} 1500 \mathrm{~m}$ \\
\hline Channel Frequency & $2.4 \mathrm{GHz}$ \\
\hline Data rate & $2 \mathrm{Mbps}$ \\
\hline No. of mobile nodes & 6 \\
\hline Mobility Model & Random Waypoint \\
\hline Data Traffic Type & CBR \\
\hline Packet size & 512 bytes,712bytes,1024bytes \\
\hline Routing Protocols & AODV, DSR and DYMO \\
\hline MAC Protocol & IEEE 802.11 \\
\hline $\begin{array}{l}\text { Physical Layer Radio } \\
\text { type }\end{array}$ & IEEE 802.11 a/g \\
\hline Antenna Model & Omni-directional \\
\hline
\end{tabular}




\section{PERFORMANCE ANALYSIS}

The animation view of Network scenario is given in Fig-1 for different On-Demand routing protocols (AODV, DSR and DYMO). With QualNet 5.0.2, the protocols comparison is performed at different parameters, and then we determine the average of readings of each parameter for each protocol. At different packet sizes ( 512 bytes, 712 bytes \& 1024bytes), the overall performance of protocols is analyzed and compared.

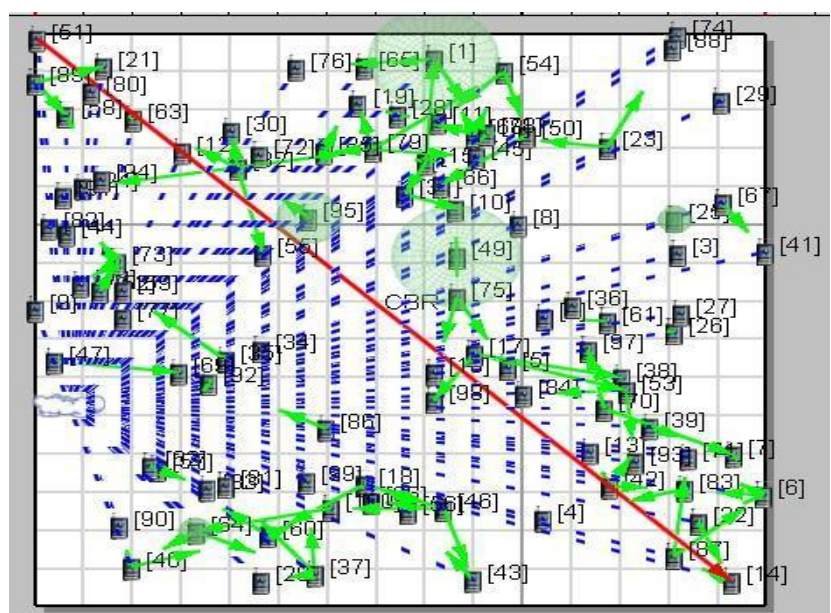

Fig 1: Animation View

\subsection{Packet Loss}

The amount of packets lost during transmission is Packet Loss. The packet loss occurs due to the incorrect path or routes and MAC layer collisions. The total packets sent and received information graph is given below for three protocols AODV, DSR and DYMO by which we can retrieve the number of packet loss at the destination:

Table 2: Total packet received

\begin{tabular}{|c|c|c|c|c|}
\hline $\begin{array}{c}\text { Packet } \\
\text { Size }\end{array}$ & $\begin{array}{c}\text { Total } \\
\text { Packet } \\
\text { Sent }\end{array}$ & $\begin{array}{c}\text { Total } \\
\text { Packet } \\
\text { Received } \\
(\text { AODV) }\end{array}$ & $\begin{array}{c}\text { Total } \\
\text { Packet } \\
\text { Received } \\
\text { (DSR) }\end{array}$ & $\begin{array}{c}\text { Total } \\
\text { Packet } \\
\text { Received } \\
\text { (DYMO) }\end{array}$ \\
\hline 512 & 20 & 11 & 16 & 17 \\
\hline 712 & 20 & 18 & 12 & 2 \\
\hline 1024 & 20 & 17 & 15 & 1 \\
\hline
\end{tabular}

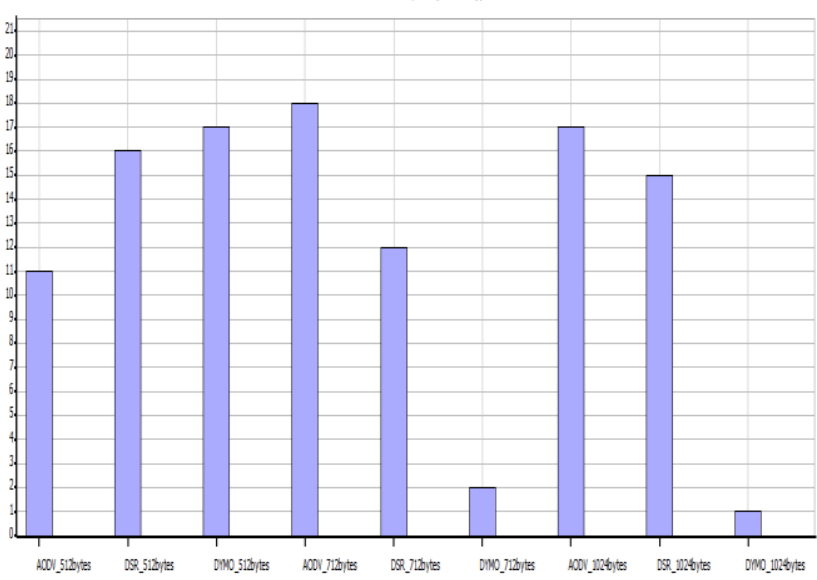

Fig 2: Total packet received vs. Packet size

By the analysis of send and receive packets for various packet sizes of different protocols, we find that average packet loss in DYMO is maximum and in AODV, it is minimum.

\subsection{Throughput}

The average rate of successful packets delivery from sender to the receiver in a communication channel is called Throughput. When we take the average of all throughputs of each protocol separately, it displays that the throughput of DSR is highest and the throughput DYMO is lowest. In figure 4 , throughput at CBR server is shown:

Table 3: Average Throughput

\begin{tabular}{|c|c|c|c|c|}
\hline $\begin{array}{c}\text { Packet } \\
\text { Size }\end{array}$ & $\begin{array}{c}\text { Total } \\
\text { Packet } \\
\text { Sent }\end{array}$ & $\begin{array}{c}\text { Throughput } \\
\text { (AODV) } \\
\text { (bits/s) }\end{array}$ & $\begin{array}{c}\text { Throughput } \\
\text { (DSR) } \\
\text { (bits/s) }\end{array}$ & $\begin{array}{c}\text { Throughput } \\
\text { (DYMO) } \\
\text { (bits/s) }\end{array}$ \\
\hline 512 & 20 & 1644 & 4367 & 4241 \\
\hline 712 & 20 & 6252 & 4557 & 3960 \\
\hline 1024 & 20 & 9041 & 8207 & 708 \\
\hline
\end{tabular}

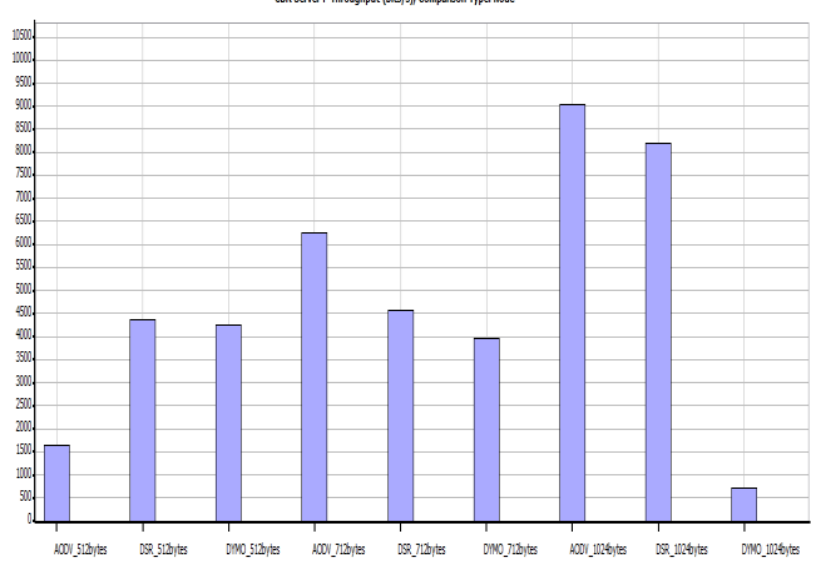

Fig 3: Average Throughput vs. Packet size

\subsection{Average End-to-End Delay}

The amount of time taken by a packet to transfer from a source to destination in a network is refers as Average End To - End Delay. So, it should be less. The average End-to-End Delay is worst in DYMO protocol and best in DSR.

Table 4: Average End to End Delay

\begin{tabular}{|l|l|l|l|l|}
\hline $\begin{array}{l}\text { Packet } \\
\text { Size }\end{array}$ & $\begin{array}{l}\text { Total } \\
\text { Packet } \\
\text { Sent }\end{array}$ & $\begin{array}{l}\text { Average } \\
\text { End-to- } \\
\text { End } \\
\text { Delay(sec) } \\
\text { (AODV) }\end{array}$ & $\begin{array}{l}\text { Average } \\
\text { End-to- } \\
\text { End Delay } \\
\text { (sec) } \\
\text { (DSR) }\end{array}$ & $\begin{array}{l}\text { Average } \\
\text { End-to-End } \\
\text { Delay (sec) } \\
\text { (DYMO) }\end{array}$ \\
\hline 512 & 20 & 0.107353 & 0.0145315 & 0.0452112 \\
\hline 712 & 20 & 0.0443932 & 0.0159941 & 1.51404 \\
\hline 1024 & 20 & 0.0492111 & 0.0234979 & 0.443478 \\
\hline
\end{tabular}

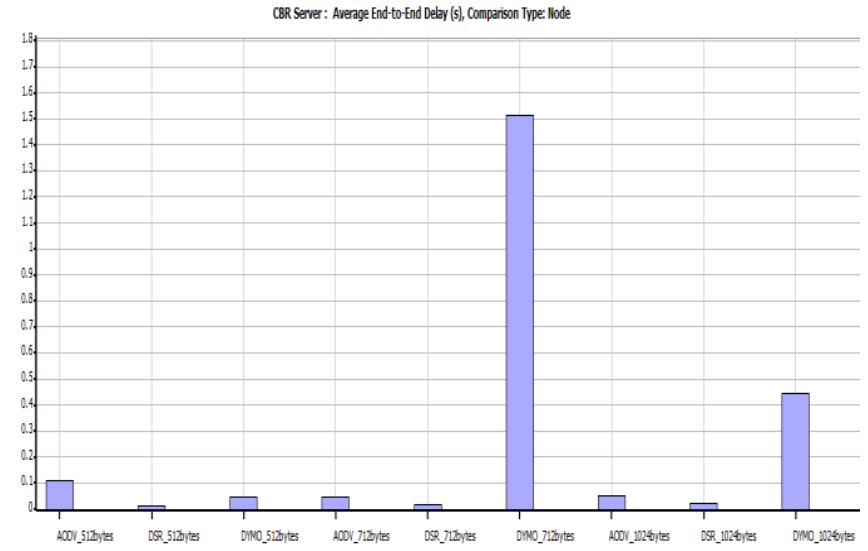

Fig 4: Average End to End Delay vs. Packet size 


\subsection{Aggregate Good put}

In application layer, the amount of data successfully transmitted in bits per second from source to destination is calculated as Aggregate Good put. The aggregate good put of AODV is best in this simulation results then DSR perform well and least performance is by DYMO.

Table 5: Aggregate good put

\begin{tabular}{|l|l|l|l|l|}
\hline $\begin{array}{l}\text { Packet } \\
\text { Size }\end{array}$ & $\begin{array}{l}\text { Total } \\
\text { Packet } \\
\text { Sent }\end{array}$ & $\begin{array}{l}\text { Goodput } \\
\text { (AODV) }\end{array}$ & $\begin{array}{l}\text { Goodput } \\
\text { (DSR) }\end{array}$ & $\begin{array}{l}\text { Goodput } \\
\text { (DYMO) }\end{array}$ \\
\hline 512 & 20 & 5632 & 8192 & 8704 \\
\hline 712 & 20 & 12816 & 8544 & 1424 \\
\hline 1024 & 20 & 17408 & 15360 & 1024 \\
\hline
\end{tabular}

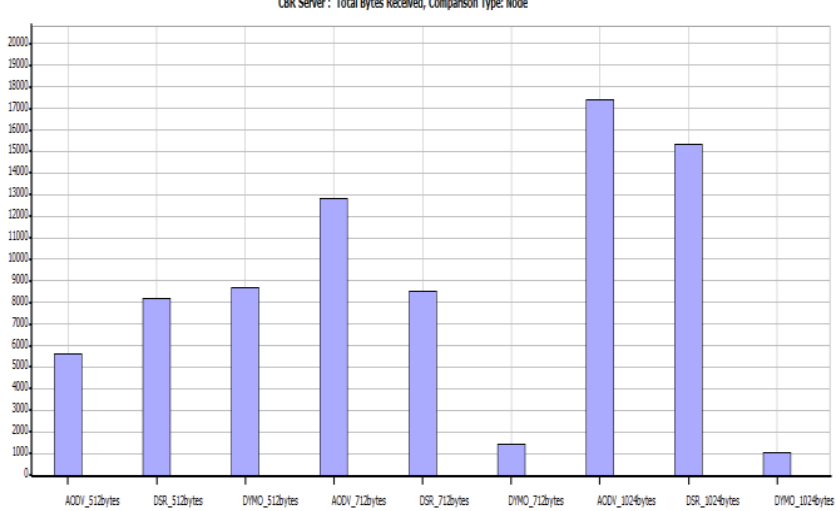

Fig 5: Aggregate good put vs. Packet size

\subsection{Average Jitter}

It is the variation in time between packets caused by network congestion or route changes. It should be less for a routing protocol to perform better. The reason for jitter is network congestion, route changes or timing drift due to which there occurs a delay between packets.

Table 6: Average Jitter

\begin{tabular}{|c|c|c|c|c|}
\hline $\begin{array}{c}\text { Packet } \\
\text { Size }\end{array}$ & $\begin{array}{c}\text { Total } \\
\text { Packet } \\
\text { Sent }\end{array}$ & $\begin{array}{c}\text { Average } \\
\text { Jitter } \\
\text { (AODV) } \\
\text { (sec) }\end{array}$ & $\begin{array}{c}\text { Average } \\
\text { Jitter } \\
\text { (DSR) } \\
\text { (sec) }\end{array}$ & $\begin{array}{c}\text { Average } \\
\text { Jitter } \\
\text { (DYMO) } \\
\text { (sec) }\end{array}$ \\
\hline 512 & 20 & 0.0456318 & 0.00294159 & 0.0188757 \\
\hline 712 & 20 & 0.0186692 & 0.00146719 & 0.0769084 \\
\hline 1024 & 20 & 0.0187658 & 0.00452285 & 0.0224677 \\
\hline
\end{tabular}

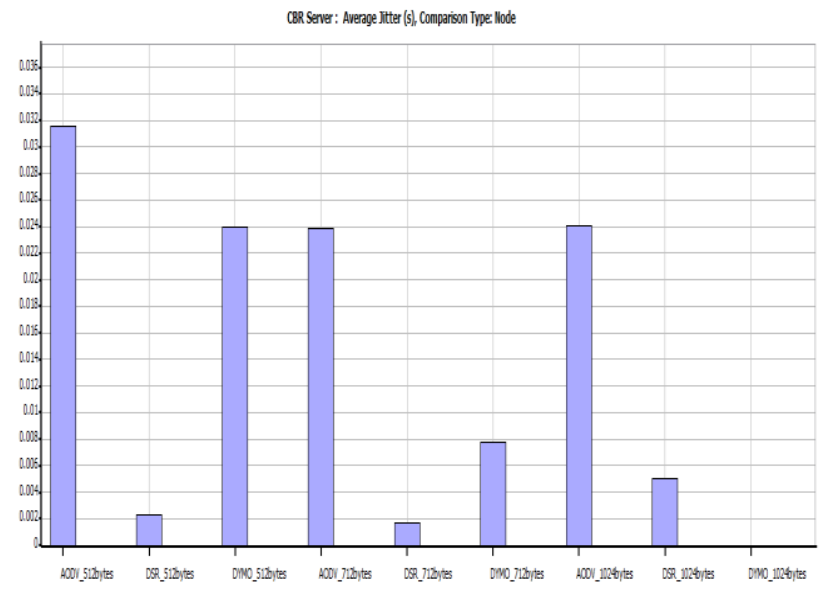

Fig 6: Average Jitter vs. Packet size
In AODV, There is maximum Jitter as source node initiates route discovery mechanism by broad casting a route request packets to its neighbors. In this simulation result DSR has very less average jitter than and DYMO and AODV.

\section{CONCLUSION}

Using QualNet 5.0.2, the performance and analysis of AODV, DSR and DYMO protocols is evaluated with varying packet sizes ( 512 bytes, 712 bytes and 1024 bytes). The performance is observed on the basis of End-To-End Delay, Throughput, Packet Loss and Good put with CBR load (Packet size, End time, start time and total packet send) using QualNet 5.0.2 simulator on Windows platform.

From the performance evaluation, the results obtained are as follows:

1) Throughput is highest for DSR and lowest for DYMO protocols.

2) DSR gives shortest average end-to-end delay and DYMO gives highest.

3) DSR has shortest average jitter and AODV has highest.

4) DYMO gives maximum Average packet loss and AODV gives minimum.

5) Good put is highest for AODV and is least for DYMO. This result will be helpful to understand the mobility and traffic load for different layers. For the future work, we will take different simulation scenarios and will cover other protocols also.

\section{ACKNOWLEDGMENTS}

From the core of my heart I am thankful to Gurukul Kangri University, Haridwar for providing a research platform. I am thankful to G. B. Pant Engineering College, Pauri for being always supportive.

\section{REFERENCES}

[1] Vivek Thaper, Bindyia Jain and Varsha Sahni. August 2011. Performance Analysis of Ad Hoc Routing Protocols Using Random Waypoint Mobility Model in Wireless Sensor Networks. IJCSE.

[2] MIAO Quan-xing, XU Lei. 2010. DYMO routing protocol Research and Simulation based on NS2. International conference on computer application and system modelling (ICCASM 2010),pp. v14-41 -v14-44.

[3] C. K. Toh. 2002:55-77. Ad hoc Mobile Wireless Networks: Protocols and Systems. Prentice Hall PTR.

[4] Mbarushimana C., Shahrabi A., "Comparative Mbarushimana C., Shahrabi A. 2007. Comparative Study of Reactive and Proactive Routing Protocols Performance in Mobile Ad Hoc Networks. 21st International Conference on Advanced Information Networking and Applications Workshops, Vol. 2, Pages: 679-684.

[5] Pirzada, A.A., Portmann, M., Indulska, J. 2006.Performance Comparison of Multi-Path AODV and DSR protocols in Hybrid Mesh Networks. 14th IEEE International Conference on Networks, vol. 02, Pages: 16.

[6] Bai, Fan; Helmy, Ahmed. 2006. A Survey of Mobility Models in Wireless Ad hoc Networks. (Chapter 1 in Wireless Ad-Hoc Networks. Kluwer Academic. 2006).

[7] N.S. Yadav, and R.P.Yadav. 2007. Performance Comparison and Analysis of Table- Driven and On- 
Demand Routing Protocols for Mobile Ad-hoc Networks. International Journal of Information Technology, Vol.4, No. 2, pp 101-109.

[8] A.A. Pirzada, C. McDonald, and A. Datta. 2006. Performance Comparison of Trust-Based Reactive Routing Protocols. IEEE Transactions on Mobile Computing Vol. 5 No.6 pp. 695-710.

[9] Elizabeth Belding, Royer, "Routing approaches in mobile ad hoc networks", in: S. Basagni, M.Conti, S. Giordano, I. Stojemenvoic (Eds), AdHoc Networking, IEEE Press Wiley, New York, 2003.

[10] S.Y. Ni, Y.C. Tseng, Y.S. Chen, J.P. Sheu. August 1999. The broadcast storm problem in a mobile ad hoc network, in: Proceedings of the 1999 Fifth Annual ACM/IEEE International Conference on Mobile Computing and Networking, IEEE Computer Society, New York, pp. 151-162.

[11] QiZhang, Dharma P. Agrawal. February 2005. Dynamic probabilistic broadcasting in MANETs. Journal of Parallel and Distributed Computing 65(2), pp 220-233.

[12] B.Williams, T. Camp. 2002. Comparison of broadcasting techniques for mobile ad hoc networks, in: Proceedings of the ACM International Symposium on Mobile Ad Hoc Networking and Computing (MOBIHOC 2002), pp. 194-205.
[13] Perkins C, Bhagwat P. October1994. Highly Dynamic Destination-Sequenced Distance-Vector Routing (DSDV) Routing. SIGCOMM' 94 Computer Communication Review, vol24, no.4, p234-244.

[14] Charles Perkins, Elizabeth Royer and Samir Das. July 2003. Ad hoc one demand distance vector (AODV) routing. IETF RFC No. 3561.

[15] Josh Broch, David Johnson and David Maltz. Feb 2007. The dynamic source routing protocol for mobile adhoc networks for IPv4. IETF RFC 4728.

[16] D. Johnsonand, D. Maltz. 1996. Dynamic source routing in ad hoc wireless networks. In T. Imielinski and $\mathrm{H}$. Korth, editors, Mobile computing, chapter5. Kluwer Academic.

[17] Ian D. Chakeresand Charles E. Perkins. October 2006.Dynamic MANET on demand (DYMO) routing protocol. Internet-Draft Version 06, IETF.

[18] V. Park, and S. Corson. July 2001. Temporally-Ordered Routing Algorithm (TORA). Version 1 Functional Specification, draft-ietf-manet-tora-spec-04.txt.

[19] Zygmunt J. Haas, Marc R. Pearlman and Prince Samar. July, 2002. The Zone Routing Protocol (ZRP) for Ad Hoc Networks. Draft-ietf-manet-zone-zrp-04.txt. 